\title{
Analysis of the effects of pharyngeal flap surgery on reducing hypernasality in patients with velopharyngeal insufficiency
}

\author{
Nader Saki ${ }^{1}$, Fatemeh Lalvand ${ }^{2}$, Soheila Nikakhlagh ${ }^{1}$, Leila Sistani Karampour ${ }^{3}$
}

\begin{abstract}
Background and Objectives: Velopharyngeal insufficiency (VPI) occurs in 25 to $43 \%$ of patients that undergo cleft palate repair. This disorder has a variety of signs including variations in nasal resonance (hypernasality), misarticulating, turmoil in nasal emissions, and grimacing. VPI can considerably affect social relations and the mental health of patients. Numerous methods have been developed for the treatment of VPI such as speech therapy, continuous positive airway pressure (CPAP), prosthetic treatment, and surgical interventions. The most common method, especially in the past three decades, has been the pharyngeal flap method. The objective of this study was to study the effects of the pharyngeal flap surgical method on the treatment of hypernasality which is a measureable sign of velopharyngeal insufficiency.

Methods \& Materials: In this cross-sectional study, a total of 112 patients with pharyngeal sphincter insufficiency who aged between 3 and 25 and had visited the otorhinolaryngology clinic of Imam Hospital of Ahvaz were studied from 2008 to 2015. The severity of hypernasality was measured by three speech therapists based on a universal parameter before the superior based pharyngeal flap surgery and 3 to 12 months after the surgery. The significance level for the aforementioned statistical tests was 0.05 . Data was also analyzed using SPSS 16.

Results: Following the superior based pharyngeal flap surgery, improved hypernasality, mild hypernasaliy, severe hypernasality, and hyponasality were observed in $42 \%, 6.44 \%, 6.11 \%$ and $8.1 \%$ of the patients, respectively. None of the 19 -year old or older patients showed improvement of hyponasality and only patients aged between 3 and 6 years showed hyponasality. However, statistical analyses revealed that there was no significant difference between the responses of patients with different ages to treatment with superior based pharyngeal flap surgery $(p=671)$.

Conclusion: Results of the present study suggest that 12 months after pharyngeal flap surgery almost $87 \%$ of patients experience a complete or relative improvement of hypernasality. This finding complies with the findings of numerous previous studies.
\end{abstract}

Keywords: velopharyngeal insufficiency, pharyngeal flap, hypernasality, outcome

\section{INTRODUCTION}

Cleft palate is one of the most common head and neck congenital diseases with a prevalence of one in every 700 live births. Among the patients, $25-43 \%$ of those who undergo the surgery for cleft palate repair develop velopharyngeal inadequacy $(1,5)$. The Velopharynx is a space which connects the oral pharynx to the nasal pharynx. It ends to the velum (soft palate) in the front, the posterior pharyngeal wall from the behind, and lateral walls of the pharynx on the sides. In children, a part of the upper and lateral walls is covered with adenoids and lateral tonsils. The Velopharynx is responsible for separating the oral cavity from the nasal cavity at the time of swallowing or talking. The normal function of velopharynx relies on proper closure of the velopharynx flap and adequate consistency in the speed of flapping $(1,4)$.

Velopharyngeal inadequacy (VPI) which was described by Passavant in 1863 has a variety of signs including hypernasality, misarticulating, turmoil in nasal emissions, and grimacing. It can considerably influence social relations as well as the mental health of patients $(2,12)$. In addition to unrepaired cleft palate and repaired cleft palate other causes of VPI include submucosal cleft palate and the complications of adenoidectomy or neuromuscular disorders which are

\footnotetext{
Associate professor, Hearing Research Center, Ahvaz Jundishapur University of Medical Sciences, Ahvaz, Iran

2 General Physician, Student research committee, Ahvaz Jundishapur University of Medical Sciences, Ahvaz, Iran

3 Otolaryngologist, Hearing Research Center, Ahvaz Jundishapur University of Medical Sciences, Ahvaz, Iran
}

Correspondence: Leila Sistani Karampour

Imam hospital, Ahvaz Jundishapur University of Medical Sciences, Ahvaz, Iran

E-mail: sistani_l@yahoo.com

Received: 25 Apr 2018, Accepted: 31 Jun 2018

(C) 2019 by the authors; licensee Modestum Ltd., UK. This article is an open access article distributed under the terms and conditions of the Creative Commons Attribution License (http://creativecommons.org/licenses/by/4.0/). 
Table 1: The number of patients based on gender

\begin{tabular}{cccc}
\hline Age (year) & Number & Male & Female \\
\hline $3-6$ & 74 & 34 & 40 \\
\hline $7-10$ & 21 & 9 & 12 \\
\hline $11-14$ & 9 & 3 & 6 \\
\hline $15-18$ & 5 & 2 & 3 \\
\hline$>19$ & 3 & 1 & 2 \\
\hline
\end{tabular}

Table 2: Recovery of patients with hypernasality by age (Numbers)

\begin{tabular}{ccccc}
\hline & Improved hypernasality & Mild hypernasality & Severe hypernasality & Hyponasality \\
\hline $3-6$ years & 35 & 31 & 6 & 2 \\
\hline 7-10 years & 8 & 9 & 4 & - \\
\hline $11-14$ years & 3 & 4 & 2 & - \\
\hline $15-18$ years & 1 & 3 & 1 & - \\
\hline 19 and higher & - & 3 & - & - \\
\hline
\end{tabular}

less common $(3,4,9)$. Numerous methods have been developed for the treatment of VPI such as speech therapy, continuous positive airway pressure (CPAP), prosthetic treatment, and surgical interventions. VPI surgery has undergone numerous changes since its invention by Passavant in the nineteenth century, but the most common method especially in the past three decades has been the pharyngeal flap surgery. Other surgical methods include levator positioning, pharyngoplasty, and reinforcement of the posterior wall. Since the pharyngeal flap surgery is the most common treatment for VPI, in this research the effect of this surgical treatment on the improvement of hypernasality (which is a measureable sign of VPI) was studied.

\section{METHODS \& MATERIALS}

In this cross-sectional and non-random research, patients with VPI who visited the otorhinolaryngology clinic of Imam Hospital and aged between 3 and 25 were examined. The inclusion criteria included the following: existence of repaired cleft palate; existence of at least $75 \%$ of lingual development in accordance with age; non-syndromic cleft palate; lack of severe loss of hearing; existence of repaired palatal fistula; and lack of obstructive sleep apnea syndrome. Afterward, the severity of hypernasality of patients was examined by three speech therapists based on a universal parameter. In the next stage, all patients were operated by the same surgeon using the superior-based pharyngeal flap surgical technique. Three and twelve months following the surgery patients were invited and the severity of hypernasality was once again measured by another three speech therapist based on a universal parameter. Finally, the mean pre-operative and postoperative data were compared. Descriptive analysis of data was carried out by the use of frequency distribution tables, diagrams and numerical indices. Next, through the chi-squared test and t-test the relationship between the qualitative and quantitative variables was examined. The significance level for the aforementioned statistical tests was 0.05 . Data was also analyzed using SPSS 16. Registration ID is: IRCT2012062910136N1

\section{RESULTS}

In this study, 112 patients aged between 3 and 25 were studied. Of the 112 patients, 49 were male and 63 were female (Table 1). In addition, 109 patients had a history of cleft palate surgery and 3 patients had pharyngeal inadequacy and therefore did not respond to speech therapy because of having a short soft palate and hypernasality. The average age of patients was $89.6 \pm 14.4$ years. Moreover, $1.66 \%$ of the patients aged between 3 and $6,8.18 \%$ aged between 7 and 10 , $8 \%$ aged between 11 and 14,5.4\% aged between 15 and 18 and $7.2 \%$ aged over $19.3 .56 \%$ of the patients were female and $7.34 \%$ were male (Table 2). No significant difference was observed between the gender proportion (male and female) of participants $(P=0.186)$. Furthermore, there was no significant statistical difference between the age distributions among patients based on gender $(P=0.95)$.

Following the superior based pharyngeal flap surgeries, improved hypernasality, mild hypernasality, severe hypernasality, and hyponasality were seen in $42 \%, 6.44 \%, 6.11 \%$ and $8.1 \%$ of the patients, respectively.

None of the 19 year old or older patients showed signs of improved hypernasality; meanwhile, only patients aged between 3 and 6 were diagnosed with hyponasality. However, results of the statistical analyses revealed that no significant difference existed between the responses of patients receiving superior based pharyngeal flap surgery to treatment $(p=0.671)$. 


\section{DISCUSSION}

The Outbreak of velopharyngeal insufficiency following cleft palate is reported to vary between 0 and $50 \%$ by different studies. The reported incidence of this disorder depends on the selection of patients, experience of the surgeon, and the surgical technique $(6,10,11)$. Results of the present study showed that approximately $87 \%$ of patients experience a complete or relative improvement of hypernasality 12 months after the pharyngeal flap surgery. This finding complies with the results of previous research. In a study that was carried out by schmelzeisen et al. (1992), of the 51 patients receiving pharyngeal flap surgery 37 patients (72\%) gained normal or close to normal speech (6). Abiholme et al. carried out a multicenter study which showed that one year after pharyngeal flap surgery, hypernasality was treated in $83 \%$ of patients ( 43 of 52 patients) (7). Of the 65 patients examined by Moris et al., 43 patients (66.1\%) gained normal or close to normal speech after pharyngeal flap surgery (2). Although the results of the present study are similar to the results of previous studies in most parts of the globe, there are slight differences between our results and findings of the descriptive retrospective research by Derakhshan et al. in Isfahan University of Medical Sciences. In the aforementioned study by Derakhshan et al., which was carried out on 24 patients, only $25 \%$ of patients experienced improved hypernasality after surgery whereas different degrees of hypernasality remained in $76 \%$ of patients. That is to say, mild hypernasality, medium hypernasality, and severe hypernasaity were observed in $2.29 \%, 3.8 \%$ and $5.37 \%$ of the patients, respectively. In 6 patients (24\%), hypernasality was fully treated whereas it remained in 17 patients (68\%) (6). The hypernasality of two patients (8\%) was also immeasurable. Post-operative hyponasality was only seen in one patient (8). As mentioned, the outbreak of severe hypernasality in our study was only about $12 \%$ whereas it was $5.37 \%$ in the study by Derakhshan et al. Moreover, in our research hypernasality was completely treated or turned into mild hypernasality in about $87 \%$ of patients while in the study by Fatemeh Derakhshan hypernasality was treated or mitigated to mild hypernasality in about $55 \%$ of patients. The difference between the results can be explained by the fact that the sample used in this study was larger than the one used by Derakhshan (i.e. 112 patients were studied in this research while 23 were examined by Derakhshan (12). The reason is that the smaller sample size was associated with potential bias which could considerably influence the data.

\section{CONCLUSION}

Research results showed that pharyngeal flap surgery yields almost reliable results and leads to the recovery of a large percentage of patients when used for the treatment of velopharyngeal (VPI) in patients with cleft palate. However, larger multicenter studies with larger samples from different parts of the country and comparisons between the pharyngeal flap and other surgical procedures can be highly useful.

\section{ACKNOWLEDGEMENTS}

This article is the result of an M.D. thesis (U-89223). The project was completely funded by the Research Deputy. Authors would like to thank Research Deputy of Faculty of Medicine and Hearing Research Center.

\section{REFERENCES}

1. Pensler JM, Reich DS. A comparison of speech results after the pharyngeal flap and the dynamic sphincteroplasty procedures Ann Plast Surg. 1991 May;26(5):441-3. https://doi.org/10.1097/00000637-199105000-00005 PMid:1952716

2. Morris HL, Bardach J, Jones D, Christiansen JL, Gray SD. Clinical results of pharyngeal flap surgery: the lowa experience. Plast Reconstr Surg. 1995 Apr;95(4):652-62. https://doi.org/10.1097/00006534-199504000-00006 PMid:7892309

3. Nikakhlagh S, Rahim F, Boostani H, Shirazi STB, Saki N. The effect of Adenotonsillectomy on quality of life in adults and pediatric patients. Research Journal of Biological Sciences. 2009;4(12):1259-61. https://doi.org/10.1007/s12070-011-0244-4

4. Leuchter I, Schweizer V, Hohlfeld J, Pasche P. Treatment of velopharyngeal insufficiency by autologous fat injection. Eur Arch Otorhinolaryngol 2010;267(6):977-83. https://doi.org/10.1007/s00405-009-1157-7 PMid:20033195

5. Saki N, Ghasem Saki, Fakher Rahim, Nikakhlagh S. Incidence of head and neck birth defects in Iran; A Crosssectional study from southwest region of Iran.Pak J Med Sci 2009;25(5):770-5. 
6. Schmelzeisen R, Hausamen JE, Loebell E, Hacki T. Long-term results following velopharyngoplasty with a cranially based pharyngeal flap. Plast Reconstr Surg. 1992 Nov;90(5):774-8. https://doi.org/10.1097/00006534199211000-00006 PMid:1410029

7. Abyholm F, D'Antonio L, Davidson Ward SL, Kjøll L, Saeed M, Shaw W, Sloan G, Whitby D, Worhington H, Wyatt R; VPI Surgical Group. Pharyngeal flap and sphincterplasty for velopharyngeal insufficiency have equal outcome at 1 year postoperatively: results of a randomized trial. Cleft Palate Craniofac J. 2005 Sep;42(5):501-11. https://doi.org/10.1597/03-148.1 PMid:16149831

8. Nikakhlagh S, Tahmasebi M, Badri R, Saki N, Rahim F, Badri SH. Craniofacial variables in subjects with and without habitual snoring: A cephalometric comparison. Indian J Otolaryngol Head Neck Surg. July-September 2010; 62(3):304-9. https://doi.org/10.1007/s12070-010-0089-2 PMid:23120730 PMCid:PMC3450238

9. Lesavoy MA, Borud LJ, Thorson T, Riegelhuth ME, Berkowitz CD. Upper airway obstruction after pharyngeal flap surgery. Ann Plast Surg 1996;36(1):26-30. https://doi.org/10.1097/00000637-199601000-00006 PMid:8722980

10. Nader Saki, Sepideh Asadizadeh, Amin Konari, Soheila Nikakhlagh. Outcomes of Reconstructive Surgery for Cleft Palate Patients: A survey on patients Admitted to Imam Khomeini and Apadana Hospitals. Biomedical \& pharmacology journal. 2015;8(2):1141-4. https://doi.org/10.13005/bpj/869

11. Dejonckere $\mathrm{PH}$, van Wijngaarden HA. Retropharyngeal autologous fat transplantation for congenital short palate: a nasometric assessment of functional results. Ann Otol Rhinol Laryngol 2001;110 (2):168-72. https://doi.org/10.1177/000348940111000213 PMid:11219525

12. Fatemeh $D$, Marziyeh $P$. The study of speech disorders and middle ear diseases following primary palatoplasty in children with cleft palate. Journal of Isfahan medical school. May 2011;29(130):222-9.

$\diamond \diamond \diamond \diamond \diamond \diamond \diamond$

http://www.ejgm.co.uk 